\title{
Pemanfaatan Metode Triple Exponential Smoothing Dalam Peramalan Penjualan Pada PT.Dinamika Daya Segara Malang
}

\author{
Tutur Ade Tistiawan', Titania Dwi Andini ${ }^{2}$ \\ STMIK ASIA Malang \\ ${ }^{1}$ generioda@gmail.com, ${ }^{2}$ titania@asia.ac.id
}

\begin{abstract}
ABSTRAK.PT. Dinamika Daya Segara Malang merupakan salah satu perusahaan yang bergerak di bidang marketing. Dalam hal ini, penjualan produk akan menjadi sorotan utama. Dikarenakan tiap daerah mendapat target baik bulanan maupun per semester dari kantor pusat. Selain itu pada perusahaan ini belum ada sistem yang menunjang untuk peramalan penjualan pada periode berikutnya. Dalam menentukan metode peramalan yang sesuai terlebih dahulu haruslah mengetahui pola data dari data yang akan digunakan sebagai acuan dalam peramalan. Adapun salah satu data penjualan dari PT. Dinamika Daya Segara Malang yaitu sabun Cream detergent Ekonomi / Wings Biru 900K selama periode Januari 2013 sampai April 2016 yang dijadikan objek dalam contoh perhitungan dalam penelitian kali ini. Dari data diperoleh pola data menunjukkan grafik pasang surut. Maka proses peramalan pada jurnal ini menggunakan metode Triple Exponential Smoothing. Adapun dalam proses perhitungan peramalan digunakan konstanta alfa antara 0.1 sampai dengan 0.9. Untuk menghitung nilai kesalahan tiap alfa betujuan untuk mendapatkan nilai kesalahan minimum yang akan digunakan sebagai peramalan terbaik. Berdasarkan hasil akhir peramalan didapatkan nilai Mean Absolute Percentage Error (MAPE) terkecil adalah sebesar 10.04\% dengan menggunakan konstanta alfa 0.1 dan hasil peramalan pada bulan Mei 2016 adalah 96.22 box. Selain itu dengan andanya aplikasi yang dibangun diharapkan dapat membantu pihak perusahaan dalam mengetahui hasil ramalan jumlah penjualan di masa akan datang serta dapat membantu dalam menentukan strategi penjualan guna mencapai pada periode berikutnya.
\end{abstract}

Kata Kunci: Peramalan, Penjualan, Triple Exponential Smoothing

ABSTRACT. PT. Dinamika Daya Segara Malang is one of a company that engages in marketing sector. Selling out the products will be the main purpose of the company. Because each district company would got both monthly and semester target from the main office. Besides that, in this office does not have supporting forecasting system sales in the next period. To determine the right forecasting method, writer needs to understand the data pattern used in the experiment. As for one of the selling out product at PT. Dinamika Daya Segara Malang is Cream detergent Ekonomi / Wings Biru 900K soap in the January 2013 - April 2016 period will be the object for the example calculation in this journal. From the data, it gained unstable pattern. So, forecasting process in this report using Triple Exponential Smoothing method. As for calculation, forecasting process used constant alpha $0.1-0.9$. Calculating an error for each alpha is intended to get minimum error, so that it will be better forecasting.

By the calculation forecasting calculations result is gets the smallest mean absolute percentage error (MAPE) is $10.04 \%$ uses constant alpha 0.1 and the outcome in May 2016 is 96.22 boxes. So by using forecasting system in this company might be help to get forecasting in the next period sales and determining selling out strategy in the next period. Keywords: Forecasting, Selling, Triple Exponential Smoothing

\section{PENDAHULUAN}

PT. Dinamika Daya Segara Distrik Malangmerupakan salah satu perusahaan yang bergerak di bidang marketing atau lebih tepat bisa dikatakan sebagai distributor barang. Dalam hal ini, penjualan produk akan menjadi sorotan utama yang akan dievaluasi dari hari ke hari, bulan ke bulan serta tahun demi tahun. Setiap bulan, distrik akan mendapat target penjualan dari kantor pusat. Dimana target sangatlah jarang mengalami penurunan dan dari kebanyakan target akan selalu meningkat.

Berdasarkan data penjualan yang diperoleh,penjualan tidak akan selalu konstan maupun mengalami trend naik tiap periode. Dimana selama ini penjualan yang terjadi mengalami pasang surut. Adapun beberapa faktor yang dapat mempengaruhi penjualan yang terjadi antara lain seperti promo yang berlangsung, kenaikan harga, pengembalian barang dari toko atau return penjualan,dan lain-lain. Di samping itu juga, pada perusahaan ini belum terdapat sebuah sistem yang digunakan dalam meramalkan sebuah hasil penjualan yang akan datang.

Dari permasalahan yang telah disampaikan pada halaman sebelumnya, maka diperlukannya suatu sistem dengan metode tertentu yang dapat membantu dalam proses peramalan stok barang. Pada tahun (2009) Edyasyahputralubis, meramalkan produksi kelaa sawit menggunakan metode double eksponensial smoothing, begitu juga metode ini juga pernah dikaji oleh Andini, dkk (2016) untuk meramalkan jumlah stok alat tulis kantor di UD Achmad Jaya. Selain itu, metode eksponential smoothing juga dikaji oleh Iqbal pada 
tahun (2016) dalam proses penerapan metode triple eksponential smoothing untuk menentukan stok bahan spare part motor di Garuda Motor Jogja. Dalam kajian lain metode triple eponential smoothing juga digunakan oleh Jayanti, dkk (2015) dalam sistem penentuan peramalan stok obat.

Oleh karena itu, metode ini dapat digunakan dan dimanfaatkan untuk meramalkan pada objek penelitian dengan data pada PT. Dinamika Daya Segara Distrik Malang. Dilihat dari data yang diperoleh, maka metode yang dapat digunakan dalam kajian ini adalah metode Triple Exponential Smoothing karena karakteristik data sesuai dengan penelitian-penelitian sebelumnya (Andini dan Probo, 2016).

\section{HASIL DAN PEMBAHASAN}

\subsection{Data Penjualan}

Untuk implementasi peramalan jumlah penjualan, data yang digunakan adalah data penjualan Cream Det Ekonomi atau Wings Biru 900K selama bulan Januari 2013 sampai dengan bulan April 2016. Dimana data dapat dilihat pada Tabel 1 sebagai berikut:

Tabel 1. Data Penjualan Cream Det Ekonomi / Wings Biru 900K

\begin{tabular}{|c|c|c|c|}
\hline Month & & Sales Mat Group 2 & Qty \\
\hline Jan 2013 & 332 & CREAM DET EKONOMI/WB 900K & 42.75 \\
\hline Feb 2013 & 332 & CREAM DET EKONOMI/WB 900K & 37.42 \\
\hline Mar 2013 & 332 & CREAM DET EKONOMI/WB 900K & 50.25 \\
\hline Apr 2013 & 332 & CREAM DET EKONOMI/WB 900K & 36.00 \\
\hline May 2013 & 332 & CREAM DET EKONOMI/WB 900K & 40.00 \\
\hline Jun 2013 & 332 & CREAM DET EKONOMI/WB 900K & 42.75 \\
\hline Jul 2013 & 332 & CREAM DET EKONOMI/WB 900K & 46.42 \\
\hline Aug 2013 & 332 & CREAM DET EKONOMI/WB 900K & 43.42 \\
\hline Sep 2013 & 332 & CREAM DET EKONOMI/WB 900K & 54.83 \\
\hline Oct 2013 & 332 & CREAM DET EKONOMI/WB 900K & 49.25 \\
\hline Nov 2013 & 332 & CREAM DET EKONOMI/WB 900K & 53.67 \\
\hline Dec 2013 & 332 & CREAM DET EKONOMI/WB 900K & 43.33 \\
\hline Jan 2014 & 332 & CREAM DET EKONOMI/WB 900K & 54.92 \\
\hline Feb 2014 & 332 & CREAM DET EKONOMI/WB 900K & 48.67 \\
\hline Mar 2014 & 332 & CREAM DET EKONOMI/WB 900K & 52.25 \\
\hline Apr 2014 & 332 & CREAM DET EKONOMI/WB 900K & 52.75 \\
\hline May 2014 & 332 & CREAM DET EKONOMI/WB 900K & 60.00 \\
\hline Jun 2014 & 332 & CREAM DET EKONOMI/WB 900K & 48.50 \\
\hline Jul 2014 & 332 & CREAM DET EKONOMI/WB 900K & 41.50 \\
\hline Aug 2014 & 332 & CREAM DET EKONOMI/WB 900K & 51.33 \\
\hline Mar 2015 & 332 & CREAM DET EKONOMI/WB 900K & 64.17 \\
\hline Apr 2015 & 332 & CREAM DET EKONOMI/WB 900K & 67.50 \\
\hline May 2015 & 332 & CREAM DET EKONOMI/WB 900K & 74.08 \\
\hline Jun 2015 & 332 & CREAM DET EKONOMI/WB 900K & 69.00 \\
\hline Jul 2015 & 332 & CREAM DET EKONOMI/WB 900K & 72.58 \\
\hline Aug 2015 & 332 & CREAM DET EKONOMI/WB 900K & 100.17 \\
\hline Sep 2015 & 332 & CREAM DET EKONOMI/WB 900K & 79.33 \\
\hline Oct 2015 & 332 & CREAM DET EKONOMI/WB 900K & 89.25 \\
\hline Nov 2015 & 332 & CREAM DET EKONOMI/WB 900K & 94.92 \\
\hline Dec 2015 & 332 & CREAM DET EKONOMI/WB 900K & 90.25 \\
\hline Jan 2016 & 332 & CREAM DET EKONOMI/WB 900K & 103.83 \\
\hline Feb 2016 & 332 & CREAM DET EKONOMI/WB 900K & 75.50 \\
\hline Mar 2016 & 332 & CREAM DET EKONOMI/WB 900K & 80.50 \\
\hline Apr 2016 & 332 & CREAM DET EKONOMI/WB 900K & 95.25 \\
\hline
\end{tabular}




\subsection{Data Plot}

Data Penjualan Shampoo Cream Det Ekonomi / Wings Biru 900K selama bulan Januari 2013 sampai dengan bulan April 2016 menunjukkan kenaikan atau pasang surut seperti pada grafik yang ditunjukkan di gambar 1 .

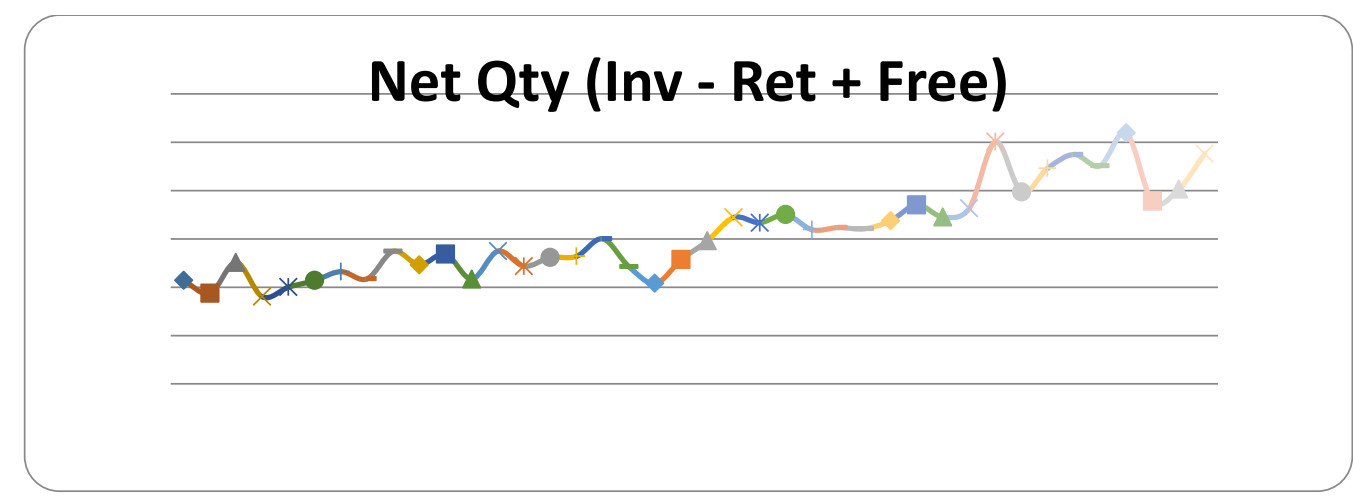

Gambar 1. Data Penjualan Shampoo Cream Det Ekonomi / Wings Biru 900K bulan Januari 21013-bulan April 2016

\subsection{Penentuan Model}

Oleh karena itu, berdasarkan data plot di atas dapat ditentukan bahwa penelitian ini menggunakan metode yang digunakan dalam proses peralam penjualan periode berikutnya adalah metode Tripe Exponential Smoothing

\subsubsection{Flowchart}

Untuk penerapan peramalan dengan metode penghalusan triple exponential smoothing dilihat pada flowchart seperti pada Gambar 2.

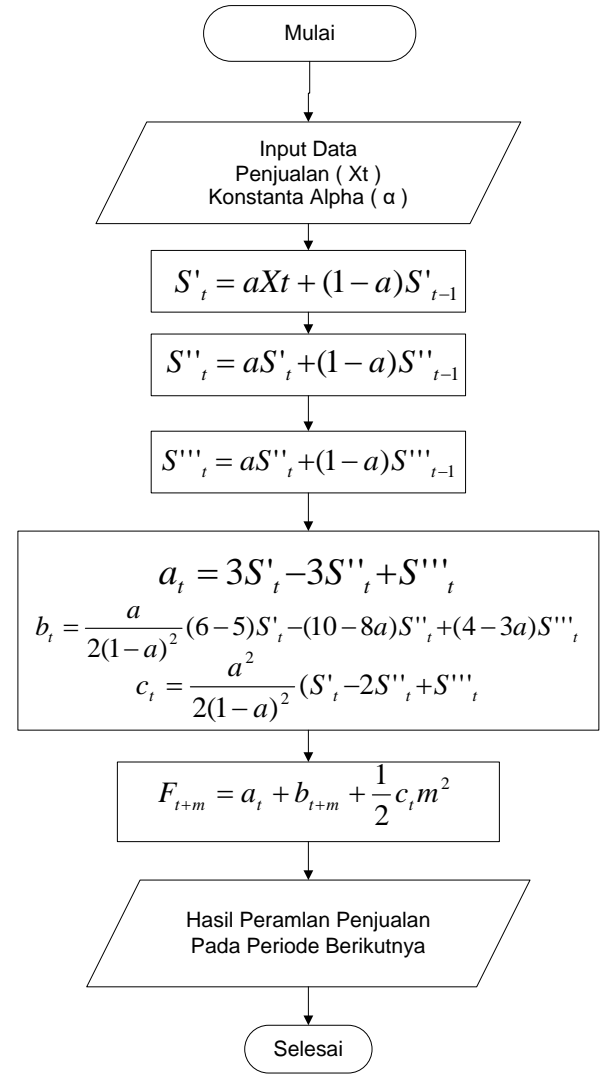

Gambar 2. Flowchart peramalan metode Triple Exponential Smoothing 
Untuk penerapan peramalan dengan metode penghalusan triple exponential smoothing sebagai berikut .

1. Menginputkan data penjualan awal periode sampai data terakhir dan konstanta alpha $(\alpha)$.

2. Mencari nilai pelumusan tunggal $S_{t}^{\prime}=a X t+(1-a) S_{t-1}^{\prime}$

3. Mencari nilai pelumusan ganda atau Double Exponential Smoothing yaitu dengan rumus $S^{\prime \prime}{ }_{t}=a S^{\prime}{ }_{t}+(1-a) S^{\prime \prime}{ }_{t-1}$

4. Mencari nilai pelumusan tiga atau Triple Exponential Smoothing yaitu dengan rumus $S^{\prime \prime \prime}{ }_{t}=a S^{\prime \prime}{ }_{t}+(1-a) S^{\prime \prime}{ }^{\prime}{ }_{t-1}$

5. Mencari nilai parameter pemulusan yaitu dengan rumus $a_{t}=3 S^{\prime} t_{t}-3 S^{\prime \prime}{ }_{t}+S^{\prime \prime}{ }^{\prime} t$

6. Mencari nilai parameter pemulusan trend linier yaitu dengan rumus

$$
b_{t}=\frac{a}{2(1-a)^{2}}(6-5) S^{\prime}{ }_{t}-(10-8 a) S^{\prime \prime}{ }_{t}+(4-3 a) S^{\prime \prime}{ }^{\prime \prime} t
$$

7. Mencari nilai parameter pemulusan trend parabaolik yaitu dengan rumus

$$
c_{t}=\frac{a^{2}}{(1-a)^{2}}\left(S^{\prime}{ }_{t}-2 S^{\prime \prime}{ }_{t}+S^{\prime \prime}{ }^{\prime}{ }_{t}\right)
$$

8. Menghitung hasil peramalan yaitu menggunakan dengan rumus $F_{t+m}=a_{t}+b_{t+m}+\frac{1}{2} c_{t} m^{2}$

9. Selesai

Masalah yang muncul dalam setiap metode pemulusan exponential adalah jika parameter pemulusan $\alpha$ tidak mendekati nol (0), pengaruh dari proses inisialisasi ini akan mempengaruhi hasil dari pemulusan exponential ketika digunakan untuk meramalkan siklus jangka panjang. Tetapi jika $\alpha$ mendekati nol (0) proses inisialisasi $\alpha$ dapat memainkan peranan yang nyata dalam suatu siklus jangka panjang. Pada penelitian ini untuk mempermudah membandingkan nilai galat (nilai kesalahan) maka nilai $\alpha$ yang digunakan $\alpha=0.1$ sampai dengan $\alpha=0.9$, dimana nilai parameter $\alpha$ besarnya antara $0<\alpha<1$.

\subsection{Proses Peramalan Dengan Exponential Smoothing Parameter $\alpha=0.1$}

Parameter dimulai pada penjualan bulan Januari 2013 - April 2016 Xt pada bulan Februari $=37.42$ dan $S^{\prime}{ }_{t-1}=42.75$. Perhitungan single exponential smoothing seperti persamaan berikut :

$$
\begin{aligned}
& \mathrm{S}^{\prime} \mathrm{t}=\mathrm{S}_{\mathrm{t}}^{\prime}=\alpha \mathrm{X}_{\mathrm{t}}+(1-\alpha) \mathrm{S}_{\mathrm{t}-1} \\
& \mathrm{~S}^{\prime} 2=(0.1 \times 37.42)+(1-0.1) \times 42.75 \\
& \mathrm{~S}^{\prime} 2=3.742+38.475 \\
& \mathrm{~S}^{\prime} 2=42.217
\end{aligned}
$$

Dari hasil yang diperoleh S'2= 42.217 maka untuk perhitungan double exponential smoothing nya dengan S' '1= 42.75 Sebagaiberikut :

$$
\begin{array}{ll}
\mathrm{S},{ }^{\prime} 2 & =\mathrm{S},{ }^{\prime}=\alpha \mathrm{S}^{\prime} \mathrm{t}+(1-\alpha) \mathrm{S}{ }^{\prime \prime} \mathrm{t}-1 \\
\mathrm{~S}, 2 & =(0.1 \times 42.22)+(1-0.1) 42.75 \\
\mathrm{~S}, 2 & =4.222+38.475 \\
\mathrm{~S}, 2 & =42.697
\end{array}
$$

Dari hasil yang diperoleh $S$ '’ $2=42.697$ maka untuk perhitungan triple exponential smoothing nya dengan $S^{\prime, ~ ' ~} 1=42.75$ sebagai berikut:

$$
\begin{aligned}
& \mathrm{S} \text { ", } \mathrm{t} \text { CI"Sietes" } \\
& \mathrm{S} \text { '"2 }=(0.1 \times 42.697)+(1-0.1) \times 42.75 \\
& \text { S"'2 }=4.2697+38.475 \\
& \text { S"'2 }=42.7447
\end{aligned}
$$

Setelah didapatkan nilai $\mathrm{S}^{\prime 2}=3792.23, \mathrm{~S}^{\prime \prime} 2=3884.759$ dan $\mathrm{S}^{\prime \prime}{ }^{\prime} 3=3894.0119$ maka dapat dihitung nilai $\alpha t, b t$,at sebagai berikut: 
Perhitungan nilai at:

$$
\begin{aligned}
& \alpha \mathrm{t}=3 *(42.217)-3 *(42.697)+42.7447 \\
& \alpha 2=328.091+42.7447 \\
& \alpha 2=126.651-1280 \\
& \alpha 2=41.3047
\end{aligned}
$$

Perhitungan nilai bt:

$$
\begin{aligned}
& \text { bt }=\frac{a}{2(1-a)^{2}}(6-5 \alpha) S^{\prime} t-(10-8 \alpha) S^{\prime \prime} t+(4-3 \alpha) S^{\prime \prime \prime} t \\
& \mathrm{~b} 2=\frac{0.1}{2(1-0.1)^{2}}(((6-(5 \times 0.1)) \times 42.217)-((10-(8 \times 0.1)) \times 42.697)+((4-(3 \times 0.1)) \\
& \mathrm{x} 42.7447) \\
& \mathrm{b}_{2}=-0.15
\end{aligned}
$$

Perhitungan nilai dihitung nilai $c_{t}$ :

$$
\begin{aligned}
& \mathrm{c}_{\mathrm{t}} \\
& \mathrm{c}_{2}=\frac{0.1^{2}}{(1-0.1)^{2}}(42.217-(2 \times 42.697)+42.7447) \\
& \mathrm{c}_{2}=0.0123(42.217-85.394+42.7447) \\
& \mathrm{c}_{2}=0.0123 *(-0.4323) \\
& \mathrm{c}_{2}=-0.00531
\end{aligned}
$$
ke- 3 adalah:

Setelah didapatkan nilai $\mathrm{a}_{2}=41.3047, \mathrm{~b}_{2}=-0.15$ dan $\mathrm{c}_{2}=-0.00531$ makauntuk hasil peramalan bulan

$$
\begin{aligned}
& \boldsymbol{F}_{t+m}=a_{t}+b_{t+m}+\frac{1}{2} c_{t} \boldsymbol{m}^{2} \\
& \mathrm{~F}_{2}=41.3047+(-0.15)+1 / 2(-0.00531) \\
& \mathrm{F}_{2}=41.1520
\end{aligned}
$$

Berikut hasil perhitungan sebagai berikut :

Tabel 2Hasil perhitungan peramalan per bulan

\begin{tabular}{|c|c|c|c|c|c|c|c|c|c|}
\hline No & Bulan & Xt & S't & S't & S'"'t & at & bt & ct & Ft \\
\hline 1 & Jan 2013 & 42.8 & 42.8 & 42.8 & 42.8 & & & & \\
\hline 2 & Feb 2013 & 37.4 & 42.2 & 42.7 & 42.7 & 41.3 & -0.2 & 0.0 & \\
\hline 3 & Mar 2013 & 50.3 & 43.0 & 42.7 & 42.7 & 43.6 & 0.1 & 0.0 & 41.2 \\
\hline 4 & Apr 2013 & 36.0 & 42.3 & 42.7 & 42.7 & 41.6 & -0.1 & 0.0 & 43.7 \\
\hline 5 & May 2013 & 40.0 & 42.1 & 42.6 & 42.7 & 41.1 & -0.2 & 0.0 & 41.5 \\
\hline & $\ldots \ldots .$. & & & & & & & & $\ldots .$. \\
\hline
\end{tabular}

Selanjutnya ini akan dijelaskan proses perhitungan manual untuk menghitung nilai kesalahan:

A. PE(Pean Error) atau nilai persentase kesalahan hasil peramalan pada bulan ke-3 pada penjualan bulan terakhir adalah 41.15 untuk mendapatkan nilai persentase kesalahan atau galat maka data penjualan yang sebenarnya dikurangi dengan hasil ramalan kemudian dibagi dengan data penjualan sebenarnya dan dikali seratus.

$$
\begin{aligned}
\mathrm{PE} & =((41.15-50.25) / 50.25 * 100) \\
& =-18.11 \%
\end{aligned}
$$

B. MAPE (Mean Absolute Percentage Error) atau nilai tengah Untuk mendapatkan nilai MAPE, yaitu dengan menjumlahkan nilai PE absolute dari awal periode sampai akhir, kemudian dibagi dengan panjang periode.

$$
\begin{gathered}
\text { MAPE }=381.85 / 38 \\
=10.04 \%
\end{gathered}
$$

Sehingga dapat dihasilkan hasil perhitungan MAPE tiap alpha bisa dilihat pada Tabel 3. 
Tabel 3 Hasil perhitungan MAPE tiap alpha

\begin{tabular}{|c|c|c|}
\hline Alpha & $\begin{array}{c}\text { Data Hasil } \\
\text { Peramalan }\end{array}$ & MAPE \\
\hline 0.1 & 96.22 & $10.04 \%$ \\
\hline 0.2 & 90.96 & $11.09 \%$ \\
\hline 0.3 & 88.99 & $12.65 \%$ \\
\hline 0.4 & 91.82 & $14.55 \%$ \\
\hline 0.5 & 98.00 & $16.70 \%$ \\
\hline 0.6 & 105.81 & $18.85 \%$ \\
\hline 0.7 & 113.70 & $22.18 \%$ \\
\hline 0.8 & 120.04 & $26.83 \%$ \\
\hline 0.9 & 122.87 & $33.25 \%$ \\
\hline
\end{tabular}

\subsection{Pengujian Ketepatan Peramalan dengan Metode Triple Exponential Smoothing}

Untuk menguji tingkat keakurasian peramalan maka diperlukan nilai mean absolute percentage error (MAPE). Telah dijelaskan bagaimana proses perhitungan secara manual. Dimana besar kecilnya mean absolute percentage error (MAPE) dipengaruhi oleh nilai alfa. memperoleh nilai Mape yang bervariasi.Nilai mape yang dihasilkan dari setiap alfa akan dibandingkan dan nilai mape yang kecil akan digunakan sebagai hasil atau keputusan peramalan . Untuk mengetahui nilai mean absolute percentage error (MAPE) setiap alfa ada pada tabel 3 .

Dimana tabel 3 ini nilai mean absolute percentage error (MAPE) terkecil terdapat pada alfa 0.1 dengan nilai mape $10.04 \%$ dan nilai hasil peramalan penjualan Cream Det Ekonomi / Wings Biru 900K pada bulan Mei 2016 yaitu sebesar 96.99 box. Sedangkan untuk keakurasian data yaitu dengan membandingkan antara jumlah data sebenarnya (JA) dengan jumlah peramalan(JP).

Untuk menghitung hasil persentase kebenarannya, berikut adalah proses perhitungannya :

$$
\mathrm{PS}=((\mathrm{JP}-\mathrm{JA}) / \mathrm{JA}) \times 100 \%
$$

$$
\mathrm{PB}=100 \%-\mathrm{PS}
$$

Keterangan :

$\mathrm{PS}=$ Persentase Salah

$\mathrm{PB}=$ Percentase Benar

$\mathrm{JP}=$ Jumlah Berdasarkan Peramalan

$\mathrm{JA}=$ Jumlah Penjualan Sebenarnya

Adapun contoh untuk proses perhitungan jumlah persentase salah maupun benar yaitu sebagai berikut :

1. Perhitungan bulan Desember 2013

$$
\begin{aligned}
& \mathrm{PS}=((50-43.33) / 43.33) \times 100 \% \\
& \mathrm{PS}=15.39 \% \\
& \mathrm{~PB}=100 \%-15.39 \% \\
& \mathrm{~PB}=84.61 \%
\end{aligned}
$$

2. Perhitungan pada bulan Desember 2015

$$
\begin{aligned}
& \mathrm{PS}=((93-90.25) / 90.25) \times 100 \% \\
& \mathrm{PS}=3.047 \% \\
& \mathrm{~PB}=100 \%-3.047 \% \\
& \mathrm{~PB}=96.95 \%
\end{aligned}
$$

Dari proses perhitungan diatas data akan direkap ke dalam tabel keakurasian dan dibandingkan antara penjualan sebenarnya (JA) dengan jumlah berdasarkan peramalan (JP) yaitu pada bulan Desember 2013, Desember 2015 dan Mei 2016. Adapun tabel perbandingan seperti tabel 4. 
Tabel 4 Keakurasian Peramalan

\begin{tabular}{|c|c|c|c|c|c|}
\hline No & Bulan & Xt & Ft & PS & PB \\
\hline 1 & Jan 2013 & 42.75 & & & \\
\hline 2 & Feb 2013 & 37.42 & & & \\
\hline 3 & Mar 2013 & 50.25 & 41.15 & $18.11 \%$ & $81.89 \%$ \\
\hline 4 & Apr 2013 & 36.00 & 43.72 & $-21.44 \%$ & $78.56 \%$ \\
\hline 5 & May 2013 & 40.00 & 41.51 & $-3.78 \%$ & $96.22 \%$ \\
\hline 6 & Jun 2013 & 42.75 & 40.94 & $4.24 \%$ & $95.76 \%$ \\
\hline 7 & Jul 2013 & 46.42 & 41.31 & $11.00 \%$ & $89.00 \%$ \\
\hline 8 & Aug 2013 & 43.42 & 42.72 & $1.60 \%$ & $98.40 \%$ \\
\hline 9 & Sep 2013 & 54.83 & 42.96 & $21.65 \%$ & $78.35 \%$ \\
\hline 10 & Oct 2013 & 49.25 & 46.57 & $5.44 \%$ & $94.56 \%$ \\
\hline 11 & Nov 2013 & 53.67 & 47.79 & $10.96 \%$ & $89.04 \%$ \\
\hline 12 & Dec 2013 & 43.33 & 50.05 & $-15.51 \%$ & $84.49 \%$ \\
\hline 13 & Jan 2014 & 54.92 & 48.73 & $11.26 \%$ & $88.74 \%$ \\
\hline 14 & Feb 2014 & 48.67 & 51.11 & $-5.01 \%$ & $94.99 \%$ \\
\hline 15 & Mar 2014 & 52.25 & 51.09 & $2.21 \%$ & $97.79 \%$ \\
\hline 16 & Apr 2014 & 52.75 & 52.11 & $1.22 \%$ & $98.78 \%$ \\
\hline 17 & May 2014 & 60.00 & 53.02 & $11.63 \%$ & $88.37 \%$ \\
\hline 18 & Jun 2014 & 48.50 & 55.88 & $-15.21 \%$ & $84.79 \%$ \\
\hline 19 & Jul 2014 & 41.50 & 54.66 & $-31.71 \%$ & $68.29 \%$ \\
\hline 20 & Aug 2014 & 51.33 & 51.51 & $-0.35 \%$ & $99.65 \%$ \\
\hline 21 & Sep 2014 & 59.17 & 51.88 & $12.31 \%$ & $87.69 \%$ \\
\hline 22 & Oct 2014 & 68.83 & 54.50 & $20.83 \%$ & $79.17 \%$ \\
\hline 23 & Nov 2014 & 66.67 & 59.45 & $10.82 \%$ & $89.18 \%$ \\
\hline 24 & Dec 2014 & 70.00 & 62.72 & $10.40 \%$ & $89.60 \%$ \\
\hline 25 & Jan 2015 & 63.75 & 66.25 & $-3.92 \%$ & $96.08 \%$ \\
\hline 26 & Feb 2015 & 64.67 & 67.10 & $-3.76 \%$ & $96.24 \%$ \\
\hline 27 & Mar 2015 & 64.17 & 67.94 & $-5.88 \%$ & $94.12 \%$ \\
\hline 28 & Apr 2015 & 67.50 & 68.34 & $-1.25 \%$ & $98.75 \%$ \\
\hline 29 & May 2015 & 74.08 & 69.55 & $6.11 \%$ & $93.89 \%$ \\
\hline 30 & Jun 2015 & 69.00 & 72.39 & $-4.91 \%$ & $95.09 \%$ \\
\hline 31 & Jul 2015 & 72.58 & 73.01 & $-0.59 \%$ & $99.41 \%$ \\
\hline 32 & Aug 2015 & 100.17 & 74.47 & $25.66 \%$ & $74.34 \%$ \\
\hline 33 & Sep 2015 & 79.33 & 83.78 & $-5.60 \%$ & $94.40 \%$ \\
\hline 34 & Oct 2015 & 89.25 & 84.85 & $4.93 \%$ & $95.07 \%$ \\
\hline 35 & Nov 2015 & 94.92 & 88.51 & $6.75 \%$ & $93.25 \%$ \\
\hline 36 & Dec 2015 & 90.25 & 92.96 & $-3.00 \%$ & $97.00 \%$ \\
\hline 37 & Jan 2016 & 103.83 & 94.92 & $8.58 \%$ & $91.42 \%$ \\
\hline 38 & Feb 2016 & 75.50 & 100.36 & $-32.92 \%$ & $67.08 \%$ \\
\hline 39 & Mar 2016 & 80.50 & 95.99 & $-19.25 \%$ & $80.75 \%$ \\
\hline 40 & Apr 2016 & 95.25 & 93.77 & $1.56 \%$ & $98.44 \%$ \\
\hline & Total & & $33.15 \%$ & $3418.65 \%$ \\
\hline
\end{tabular}

Sedangkan untuk menghitung hasil keakurasian persentase program antara persentase salah (PS) dan persentase benar (PB) secara keseluruhan adalah sebagai berikut

$$
\mathrm{PK}=(\mathrm{JB} / \mathrm{JU})
$$

Keterangan:

$\mathrm{PK}=$ Percentase Keakurasian

JB = Jumlah Persentase Benar

$\mathrm{JU}=\mathrm{Jumlah}$ Pengujian 
Untuk menghitung hasil penjumlahan persentase keakurasian program yaitu sebagai berikut :

$$
\mathrm{PK}=(3418.65 \% / 38)=89.96 \%
$$

Dari hasil pengujian di atas, dapat diketahui bahawa perbandingan dari adata penjualan sebenarnya dengan hasil ramalan menghasilkan nilai percentase keakurasian dari data 38 bulan periode yang akan datang yang di uji yaitu $89.96 \%$.

\section{KESIMPULAN DAN SARAN}

\subsection{Kesimpulan}

Berikut ini beberapa kesimpulan berdasarkan permasalahan yang telah dijelaskan sebelumnya :

1. Dari proses perhitungan yang sudah dilakukan dengan menggunakan konstanta alfa $(\alpha) 0.1$ sampai dengan konstanta alfa $(\alpha) \quad 0.9$. Untuk memperoleh ketepatan dalam metode peramalan adalah dengan membandingkan tingkat prosentase kesalahan terkecil (Percentase Error) antara alfa( $\alpha$ ) 0.1 sampai dengan 0.9, maka hasil yang didapat adalah terdapat pada perhitungan peramalan yang menggukan konstanta alfa 0.1 .

2. Hasil nilai kesalahan untuk peramalan penjualan pada bulan terakhir dengan alfa 0.1 yang didapat adalah dengan nilai peramalan 96.22 dengan MAPE $10.04 \%$.

\subsection{Saran}

a. Sebelum menentukan metode yang digunakan untuk peramalan, terlebih dahulu dilakukan pengamatan guna menentukan pola data.

b. Dilakukan analisa atau percobaan perhitungan dengan beberapa metode peramalan seperti metode Single Exponential Smoothing, Double Exponential Smoothing sebelum menentukan metode Triple Exponential Smoothing yang akan digunakan.

c. Dari perhitungan, diharapkan sistem perhitungan ini dapat dikembangkan hingga menghasilkan perhitungan yang lebih baik, yaitu dengan melakukan analisa data yang sudah ada agar lebih lanjut untuk menentukan peramalan yang akan digunakan. Karena pengembangan sistem perhitungan data yang akan diramalkan juga dapat sangat menentukan dalam jumlah penjualan yang akan datang.

\section{DAFTAR RUJUKAN}

Assauri Softjan (2012).Teknik dan Metode Peramalan Penerapaanya Dalam Ekonomi dan Dunia Usaha. Edisi 1.Jakarta. Lembaga penerbitan Fakultas Ekonomi UI. 1984 Dalam Sistem Peramalan Curah Hujan. UPI

Andini, Titania, Probo Auristandi (2016). Peramalan Jumlah Stok Alat Tulis Kantor Di UD ACHMAD JAYA Menggunakan Metode Double Exponential Smoothing, JITIKA: Jurnal Ilmiah Teknologi dan Informasia ASIA.

Edyasyahputralubis (2009). Aplikasi Metode Pemulusan Eksponensial Ganda Dari Brown Untuk Peramalan Produksi Kelapa Sawit Pada PT. Perkebunan Nusantara III tahun 2010 Dan 2011. USU

Iqbal, Muhammad (2016),Sistem Peramalan Menggunakan MetodeTriple Exponential Smoothing untuk Stok Bahan Spare Part Motor di Garuda Motor Jajag, Journal of Undergraduate Thesis, Universitas Muhammadiyah Jember

Jayanti, Ni Ketut Dewi Ari, Yohanes Priyo Atmojo , I Gusti Ngurah Wiadnyana (2015). Penerapan Metode Triple Exponential Smoothing pada Sistem Peramalan Penentuan Stok Obat, Jurnal Sistem dan Informatika (JSI). 